\title{
Germany aims for competitive equality
}

[BONN] Biotechnology researchers, east German scientists, women and young scientists are to be the main beneficiaries of growth in the German research budget, which the Social Democrat-Green government has promised to double in five years.

"But these groups will have to compete strongly against each other for the new funds, and will in many cases have to work in collaboration with industry," Wolf-Michael Catenhusen, Germany's junior minister for research, told Nature last week.

There may also be less money for space science, as funds are diverted to pay for Germany's participation in the International Space Station (ISS) and the development of the European launcher Ariane 5.

Catenhusen served for eight years as chairman of the parliamentary science committee in the late 1980s and early 1990s.

Revealing details of the new government's plans, Catenhusen said that Germany's highly successful BioRegio competition, in which regions compete for special access to part of the existing biotechnology budget, will be continued (see Nature 379, 759; 1996). The three winners will have access to an additional DM150 million (US\$85 million) from 1999 to 2003.

The plant genome programme GABI, launched last year by the previous research minister Jürgen Rüttgers with an undefined budget, will get DM5 million this year and between DM20 million and DM25 million next year. In the future, this may rise to DM30 million. Collaboration between academics and industry will be given priority.

Direct subsidies for east Germany, whose science base was rebuilt after reunification, will end. Some east German researchers were temporarily funded through the former Wissenschaftlicher Integrationsprogramm fund. But a new competition, based on BioRegio and known as InnoRegio, will promote innovation in the new Länder (states).

East German researchers have been so well supported in recent years that they are now considered good enough to compete with west German scientists for conventional funds, says Catenhusen. "Any deficits between east and west are [now] due to a lack of industrial research [in the east]," he says.

InnoRegio will begin next year with funds of DM30 million, expected to rise to DM70 million the following year. It will reward the consortia of academic scientists and industry - particularly small and medium-sized enterprises - that present the best plans to develop new technologies. The scheme's planning phase will be supported with DM5 million put aside from this year's research budget.

The special programme for universities, called the Hochschulsonderprogramm, which

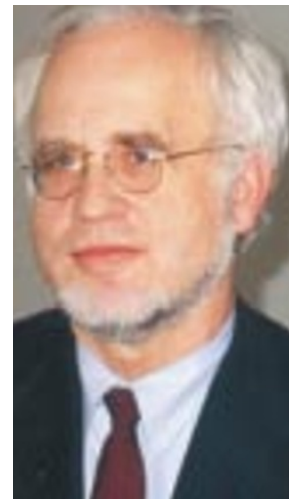

Catenhusen: boosting industrial research. the federal government set up in the late 1980 s to address problems caused by mushrooming student numbers, will not be extended beyond 2000. But the government will take over two parts of the programme that fit its own priorities: special support for women in science and for the promotion of young scientists.

The government has already put aside DM7.5 million this year for a programme called 'Equality of opportunities for women in education and research', and intends to increase this annual sum to DM12 million in 2000 and 2001. A special programme for young scientists is being planned, but details are not yet available.

Government-level discussions about making university hiring policy more flexible are also considering whether to revise rules that bar non-tenured scientists from working at a university or research institute for more than five consecutive years (see Nature 396, 396; 1998).

"The structure of our conditions of employment no longer matches the way research is conducted in practice," says Catenhusen, "in particular, [by] young people who have research grants which do not fit neatly into blocks of five years."

He does not want researchers to become permanent fixtures in a particular institute, he says, but institutes should be able to extend employment beyond five years where a portion of grant money remains to be used.

Germany's 16 national research centres, which carry out large-scale research, have a budget top-up of DM105 million, to be distributed competitively between them- selves and any partners with whom they forge links.

About half of this will go to the 'strategy fund' created two years ago by the centres' umbrella organization, the Helmholz Society, to fund projects in areas that society identifies as priorities. The rest will fund programmes supporting innovation, the development of new research areas and 'networking.

Catenhusen believes the DM15 million 'networking fund', for projects involving partners from industry or another research institute, such as a Max Planck institute, is particularly important. "National research centres have a tendency to operate in isolation," says Catenhusen, "and this extra money should encourage them to look beyond their own walls."

One loser in the distribution of the new bounty will be space science, whose budget is being held down and may be threatened more substantially in the next few years.

Research minister Edelgard Bulmahn told parliament last week that she intends to honour all international commitments to the ISS and Ariane 5. But she argued that the government should give her extra money to allow her to pay all the bills.

Without any extra money, the DM300 million domestic space science programme may be the only fund not yet fully committed, and could therefore be used to bail out the international programmes, according to ministry sources.

The domestic space budget has already seen a 10 per cent cut since 1994 , with funds for space science and astronomy falling from DM120 million to DM80 million.

Reinhard Genzel, a director at the Max Planck Institute for Extraterrestrial Physics in Garching, says: "If money is really so tight, then the government should look very carefully at the ISS commitments and consider whether some of them could indeed be revised." Space science "will suffer terribly if cuts are deepened," he says.

A lis on A bbott

\section{Head of German partic le phys ics lab dies}

[MUNICH] Björn Wiik, director of Germany's national research centre for particle physics (DESY), died last week after an accident at home.

The 62-year-old Norwegian physicist joined DESY in 1972. With three colleagues, he provided the first experimental proof of the existence of the elementary particle gluon using DESY's Positron-Electron Accelerator.

His death comes at a critical time for the future of TESLA, a 33-km superconducting linear accelerator that Wiik hoped to build at the DESY site in Hamburg by 2010. Plans for TESLA are being developed by 38 institutes in nine countries - including China, Russia and the United States - but financial support has not yet been assured.

Wiik also led the planning and construction of the Hadron-Electron Ring Accelerator, Germany's biggest research facility, which went into operation in 1992. Wiik became head of the DESY in 1993.

The research centre's directors have said that TESLA should be continued "as Wiik would have wished".

A.A. 